\title{
A cooperação entre uma ONG e os Estados "anfitriões" no controle da hanseníase na América Latina
}

\author{
Cooperation between an NGO and "host" \\ states in the control of leprosy in Latin America
}

Andreas Kalk 1

\footnotetext{
1 GTZ Rwanda. Avenue de Kiyovu, P. O. Box 59, Kigali, Rwanda. gtz-ruanda@rw.gtz.de
}

\begin{abstract}
The proliferation of nongovernmental organizations (NGOs) can be considered the result of the inability of the current democratic system to perform all the tasks desired by its citizens. Although NGOs often do quite positive work, they tend to diminish governmental power and are capable of interfering in the internal affairs of other countries. In this context, there are efforts to control their activities, and this control can produce both negative effects (blocking the defense of human rights) and positive ones (correcting the lack of coordination in the work by NGOs). NGOs working with the control of leprosy have a long history of cooperation with "host" states in Latin America. In the worst cases they work in a vacuum left by the state. In a country like Brazil, where the government prioritizes the control of Hansen disease and community participation in the political process - NGOs generally work "in harmony" with national authorities. The most useful contribution to state efforts has been the technical and financial support for training health personnel, supervision, and awareness-raising campaigns. Thus, the NGO becomes "quasi-governmental" in performing its tasks.
\end{abstract}

Key words Non-Governmental Organizations; Technical Cooperation; Leprosy

Resumo A proliferação das Organizações Não-Governamentais (ONGs), pode ser considerada como um resultado da incapacidade do sistema democrático atual de desempenhar todas as tarefas desejadas pelos seus cidadãos. Embora que as ONGs muitas vezes realizem um trabalho bastante positivo, elas têm uma tendência de diminuir o poder governamental e são capazes de interferir nos assuntos internos de outros países. Neste contexto, observam-se esforços de controlar as suas atividades e este controle pode resultar em efeitos negativos (bloqueio da defesa dos direitos humanos) e efeitos positivos (correção da falta de coordenação no trabalho das ONGs). ONGs ativas no controle da hanseníase têm uma história longa de cooperação com Estados "anfitriões" na América Latina. No pior dos casos, trabalham num vácuo deixado pelo Estado. Num país como o Brasil - onde o Governo dá prioriade ao controle da hanseníase e à participação da comunidade no processo político - as ONGs trabalham geralmente de um modo "harmônico" com as autoridades nacionais. A contribução mais útil aos esforços estaduais tem sido o apoio técnico-financeiro à capacitação do pessoal de saúde, à supervisão e às campanhas de conscientização. Assim, a ONG torna-se "quase-governamental" na execução das suas tarefas.

Palavras-chave Organização Não-Governamental; Cooperação Técnica; Hanseníase 


\section{Quais são as responsabilidades de um Governo?}

O Estado, por intermédio do Governo, geralmente desempenha tarefas que se realizam de uma maneira mais eficiente em nível coletivo do que em nível individual. Incluem-se objetivos tão diferentes como a defesa do país, a educação, a construção rodoviária e a saúde dos cidadãos. No campo da saúde, o controle de doenças contagiosas como da hanseníase é de um interesse particular, porque a enfermidade do indivíduo representa também uma ameaça direta para a sociedade. O grau de intensidade com o qual um Governo se preocupa com tais tarefas é uma das características de um bom governo.

Num país democrático, o povo controla por meio das eleições o desempenho dessas tarefas públicas. Normalmente, se tudo funcionasse bem como num "melhor dos mundos possíveis", este processo democrático da construção do poder político poderia garantir a satisfação dos cidadãos com respeito às tarefas mencionadas acima.

No entanto, a proliferação e a influência cada vez maior das Organizações Não-Governamentais (ONGs) é observada na quase totalidade dos países (Akukwe, 1998; Jareg \& Kaseje, 1998) e às vezes caracterizada como parte do fenômeno da globalização (Walt, 2001). Aparentemente, essa proliferação reflete a incapacidade do sistema democrático atual de efetuar uma certa quantidade dos trabalhos desejados pelos cidadãos dos países respectivos.

Em termos gerais, as contribuições das ONGs são bem estimadas. A importância de incluir essas organizações na planificação do governo é destacada repetitivamente (Unger \& Criel, 1995; Verhallen, 1998). A inclusão das ONGs dá voz aos interesses dos pobres (Mehrotra \& Jarrett, 2002). Entre as atividades das ONGs no setor de saúde, o controle das doenças contagiosas deve ser uma prioridade (Gellert, 1996).

O papel das ONGs é menos ambíguo quando elas atuam no seu país de origem. Sob outras designações (como "sindicatos", "associações”, “uniões”, “sociedades”), as ONGs já existiam há séculos. Nos estados laicos a maior delas sempre era a Igreja. Não obstante, o termo mais moderno "ONG" tem uma noção política que as "associações" tradicionais não tinham necessariamente. Devido a métodos muito distintos de trabalhar no campo como nas relações públicas, são capazes de chamar a atenção a uns temas completamente ignorados. Assim, elas até têm o potencial de reduzir o poder do governo (Reich, 2002).
Mais problemática ainda é a atividade crescente das ONGs em nível internacional. O que era considerado como "ajuda ao desenvolvimento" ou - mais modernamente - "cooperação técnica e financeira”, de repente pode tornar-se interferência nas políticas internas de um outro país. De um lado, as ONGs se propõem a ajudar à educação, à promoção da saúde, etc.; do outro lado podem recolher dados confidenciais dos países "anfitriões", e elas podem promover atividades e estruturas não desejadas. No caso de certos países com péssima reputação em nível internacional, tais atividades ainda podem ser protegidas pela comunidade internacional. Esse aspecto já recebe uma atenção particular na defesa dos direitos humanos (Hendriks \& Toebes, 1998). Não obstante, atividades colidindo com a legislação de um Estado anfitrião devem geralmente ser consideradas como problemáticas e contraproducentes no que se refere ao "espírito da cooperação”.

Além desses desafios maiores, as atividades das ONGs resultam em outros problemas. A falta de coordenação entre o Estado "anfitrião" e as ONGs de um lado, como entre as ONGs por si do outro, é bem documentada (Buse \& Walt, 1997). Por isso, outros autores (Kalipeni \& Oppong, 1998), exigiram até a vigilância internacional das ONGs, por exemplo, na distribuição da ajuda aos refugiados africanos.

Os sucessos das ONGs no controle das doenças contagiosas abrangem atividades tão diferentes como o controle da oncocercose (Molyneux, 2001), até o controle da hanseníase (Al-Qubati \& Al-Qubati, 1997). Neste quadro, e a pesar das suas raízes tradicionais, organizações dedicadas ao controle da hanseníase algumas vezes assumiram a função de pioneiras na cooperação com os Estados anfitriões. A necessidade de cooperar com o Estado é destacada em várias pesquisas realizadas nos países endêmicos, como na Índia (Porter et al., 2002) e no Brasil (Kalk \& König, 2002).

Atualmente, a hanseníase ou recebe uma certa atenção do Ministério da Saúde ou é completamente "relegada". Raras são as instituições governamentais que consideram inoportuna a ajuda aos pacientes da hanseníase. Por isso, no pior dos casos, ONGs dedicadas ao controle da hanseníase - como a Assistência Alemã aos Hansenianos e Tuberculosos (DAHW) - estão trabalhando num vácuo. Países como o Paraguai e a Bolívia (até um certo grau) não vêem no controle da hanseníase prioridade e proporcionam mínimos recursos a esse trabalho. Nesses países, quase a totalidade do apoio aos pacientes da hanseníase é financiado e rea- 
lizado pela DAHW e outras ONGs, incluindo organizações filantrópicas e a Igreja.

No Brasil, o quadro é completamente diferente: o controle da hanseníase é considerado como prioridade (MS, 2000a), e recebe uma atenção particular nos serviços de saúde. Simultaneamente, existem vários mecanismos estabelecidos pelo Governo Federal para fortalecer a participação das comunidades na construção do poder político (MS, 2000b; Pessoto et al., 2001). Nesse contexto, as metas do Estado "anfitrião" e da ONG dedicada ao controle da hanseníase são praticamente as mesmas. Em vários países, uma distribuição bem definida das responsabilidades entre o Estado e a ONG provou ser extremamente útil (Kalk \& König, 2002). Enquanto o Estado (no Brasil também os Estados Federais e os Municípios) cuida da infra-estrutura do sistema de saúde em geral e dos recursos humanos para a realização do trabalho, as ONGs oferecem recursos técnicos e financeiros adicionais para a capacitação do pessoal de saúde, a supervisão e as campanhas de conscientização da população. Elaboram-se projetos em conjunção com as autoridades brasileiras. Nesse ambiente de um respeito mútuo entre o Estado e a ONG, desenvolvem-se intervenções particularmente eficientes no complexo cuidado das necessidades dos pacientes. Além da poliquimioterapia, os doentes com deficiências dos nervos periféricos precisam de uma capacitação especial, de certos dispositivos ortopédicos e da reabilitação física e social. Apesar da magnitude do problema no Brasil (só a Índia tem mais casos novos de hanseníase por ano) e da extensão geográfica do terreno, conseguiu-se uma cobertura dos respectivos serviços. Assim, na cooperação com um Estado responsabilizando-se dos mesmos objetivos, a ONG continua a ser não-governamental no fornecimento dos recursos financeiros no seu país de origem, mas torna-se uma instituição quase-governamental na execução das suas tarefas.

\section{Agradecimentos}

Agradeço à Dra. Maria de Fátima Marója (Representante da Assistência Alemã aos Hansenianos e Tuberculosos - DAHW - no Brasil e funcionária da Fundação Alfredo da Matta, Manaus, Amazonas) pela leitura e sugestões apresentadas no manuscrito, e à Irmã Angela Alcalde Torrecilla (Representante da DAHW no Brasil até dezembro 2002) pelas conversas intensas refletidas no texto. 


\section{Referências}

AKUKWE, C., 1998. The growing influence of non governmental organisations (NGOs) in international health: Challenges and opportunities. Journal of the Royal Society of Health, 118:107-115.

AL-QUBATI, Y. \& AL-QUBATI, A. S., 1997. Dermatologists combat leprosy in Yemen. International Journal of Dermatology, 36:920-922.

BUSE, K. \& WALT, G., 1997. An unruly melange? Coordinating external resources to the health sector: A review. Social Science and Medicine, 45:449-463.

GELLERT, G. A., 1996. Non-governmental organizations in international health: Past successes, future challenges. International Journal of Health Planning and Management, 11:19-31.

HENDRIKS, A. \& TOEBES, B., 1998. Towards a universal definition of the right to health? Medicine and Law, 17:319-332.

JAREG, P. \& KASEJE, D. C., 1998. Growth of civil society in developing countries: Implications for health. Lancet, 351:819-822.

KALIPENI, I. \& OPPONG, J., 1998. The refugee crisis in Africa and implications for health and disease: A political ecology approach. Social Science and Medicine, 46:1637-1653.

KALK, A. \& KÖNIG, J., 2002. NGO and state: The cooperation between a leprosy relief association and other institutions in South America. Leprosy Review, 73:160-166.

MEHROTRA, S. \& JARRETT, S. W., 2002. Improving basic health service delivery in low-income countries: 'Voice' to the poor. Social Science and Medicine, 54:1685-1690.
MS (Ministério da Saúde), 2000a. Legislação sobre o Controle da Hanseníase no Brasil. Brasília: MS.

MS (Ministério da Saúde), 2000b. A Prática do Controle Social: Conselhos de Saúde e Financiamento do SUS. Brasília: MS.

MOLYNEUX, D. H., 2001. Vector-borne infections in the tropics and health policy issues in the twentyfirst century. Transactions of the Royal Society of Tropical Medicine and Hygiene, 95:233-238.

PESSOTO, U. C.; NASCIMENTO, P. R. \& HEIMANN, L. S., 2001. A gestão semiplena e a participação popular na administração da saúde. Cadernos de Saúde Pública, 17:89-97.

PORTER, J. D.; OGDEN, J. A.; RAO, P. V.; RAO, V. P.; RAJESH, D.; BUSKADE, R. A. \& SOUTAR, D., 2002. Lessons in integration - Operations research in an Indian leprosy NGO. Leprosy Review, 73:147-159.

REICH, M. R., 2002. Reshaping the state from above, from within, from below: Implications for public health. Social Science and Medicine, 54:1669-1675.

UNGER, J. P. \& CRIEL, B., 1995. Principles of health infrastructure planning in less developed countries. International Journal of Health Planning and Management, 10:113-128.

VERHALLEN, M., 1998. Involving private voluntary health care providers in 'Better Health for Africa'. World Hospitals and Health Services: The Official Journal of the International Hospital Federation, 34:19-25.

WALT, G., 2001. Globalization and health. Medicine, Conflict and Survival, 17:63-70.

Recebido em 26 de janeiro de 2003

Aprovado em 6 de fevereiro de 2003 